\title{
Adaptivity and Adaptability of Learning Object's Interface
}

\author{
Verónica Rodríguez \\ Universidad de las Américas Puebla \\ Sta. Catarina Mártir, Cholula, Puebla \\ C.P. 72820 , México
}

\author{
Gerardo Ayala \\ Universidad de las Américas Puebla \\ Sta. Catarina Mártir, Cholula, Puebla \\ C.P. 72820 , México
}

\begin{abstract}
The interface design is one of the essential elements for building a coherent and consistent learning object. However, it is still believed that interface design relates only to providing an aesthetic appearance to the learning object. The interface should be seen as the action space where mediatic objects are presented for user interaction. In this paper we introduce a architecture for adaptability and adaptivity of learning object's interface. A learning object adapts itself to the user; it is not the user who must adapt her/himself to the learning object. This adaptation implies the design of the learning object interface, which includes the processes and structures for adaptivity and adaptability. The paper includes a discussion of the architecture, its components, and a detailed description of the sequence of actions for adaptive interaction.
\end{abstract}

\section{General Terms}

Human-Computer Interaction, Information Personalization, Visualization and Multimedia, Learning Objects.

\section{Keywords}

Learning object, interface, adaptivity, adaptability, mediatic object, educational mediatic object, operational mediatic object, user model, instructional design, customization.

\section{INTRODUCTION}

Learning object interfaces usually present the same content and have the same look and feel for every user, regardless of his/her learning needs and individual characteristics. Some interfaces are "customizable"; the user can choose to modify some characteristics of the interface visual aspect. However, this does not entirely satisfy the needs of educational content presentation to the users. Aspects of content personalization, proper interaction and efficient work in the learning tasks are also important. It is also required the adaptation of the learning object interface to the needs, interests and characteristics of the user, allowing her/him to efficiently interact and perform learning activities. In order to achieve this it is necessary to consider the interests and preferences of the user, so the learning object interface can provide an appropriate support for a personalized learning experience.

According to Galeana, the adaptability of a learning object refers to its characteristic to adapt itself to the learning needs of a particular user [6]. For us, it is necessary to consider both, adaptability and adaptivity of the learning object interface. Adaptability refers to the ability of the learning object of locating content according to the user preferences, and adaptivity to the ability of presenting content according to the user interests. Preferences and interests are determined based on the interaction of the user with educational mediatic objects. In this way, the adaptivity and adaptability of the learning object interface allows a more personalized interaction and makes the user aware of her/his own learning progress [26].

\subsection{Learning Objects}

The IEEE defines leaning object as "any digital or non digital entity that can be used, reused or referenced during learning supported by technology" [15]. Wiley argues that this definition is too broad, and we are agree; he defines a learning object as "any digital resource that can be reused as support leaning" [29]. There are other definitions [5; 10; 16; 18; 23; $27 ; 28]$. Based on our studies and developments we propose the following definition: a learning object is an informative, digital and interactive entity created for generation knowledge, skills, attitudes and values, which can be adapted and reusable in different contexts.

\subsection{Mediatic Objects}

Learning objects facilitate the learning process when the user interacts with mediatic objects appropriately designed. According to Merrill, a mediatic object is "a text, graphic, video or audio presented in the learning object's interface," [17]. From our perspective, a mediatic object is a digital entity with different forms of representation which is an element of the contents presented on the learning object interface. The basic function of the mediatic object is to mediate the educational content due to its representative nature.

In our research we propose two kinds of mediatic objects: 1) Educational mediatic objects and 2) Operational mediatic objects. Educational mediatic objects show the educational content in the learning object interface. Operational mediatic objects allow the user to operate and the learning object interface.

\section{ADAPTIVITY AND ADAPTABILITY}

Advances in adaptive interfaces have improved the design and development processes of customizable user interfaces $[3 ; 13$; $14 ; 21]$.Those advances can now be applied to learning objects. According to Oppermann, adaptivity and adaptability are two features of a system which make it to be able to adapt itself, modifying its interaction with the user [21]. For Kobsa, adaptability means that the user is able to consciously personalize the application, while adaptivity refers to the selection and presentation of content done by the system, according to the user's interests [13]. Kobsa argues that the majority of software applications allow users to modify certain features "manually" to indicate their preference, while other applications are able to recognize the needs of users and respond automatically.

According to Battou [1] adaptability refers to the "capacity of adaptive learning systems (ALS) to automatically adapt the learning process to the specific requirements and preferences of a particular learner", for these authors, the adaptability is based on the granularity of the components of a learning object, where is chosen from several grains which of them are appropriate in a given situation. Gkatzidou [7] argues that learning content can be generated from adaptive aggregation 
of learning objects and their components using learning patterns. On the other hand, in $[7 ; 8]$, the authors proposes the use of design patterns for creating adaptable learning objects. In [12] the adaptivity is based on the use of competence description ontology and learner's competence records. Other authors, like $[4 ; 2 ; 20 ; 19]$ referred that the adaptivity of the learning object is accomplished by situating the learning style and preferences to the user. The learning object should consider user needs to present mediatic objects according to their learning style (auditory, pictures, text, tactile kinesthetic and internal kinesthetic.

\subsection{Adaptivity}

We consider adaptivity as the ability of the learning object interface that allows it to recommend to a specific user those educational mediatic objects believed to be of her/his interests. Adaptivity occurs progressively, as the interface records the selective actions performed by the user while interacting with the interface. These selective actions refer to the selection of specific educational mediatic objects by the user. The learning object interface shows adaptivity when it takes the decision about which educational mediatic objects are going to be recommended and presented to a specific user in a given situation. This decision is based on the user interests and the guidelines specified in the instructional design of the learning object.

\subsection{Adaptability}

We consider adaptability as the ability of the learning object interface that allows the user to modify the interface settings and adapt them to his/her preferences. The learning object interface shows adaptability when it provides the user with the possibility of freely indicates the location of educational mediatic objects on the interface. Adaptability implies the registration of the preferred location of educational mediatic objects for each specific user.

\section{LEARNING OBJECT INTERFACE}

Adaptivity and adaptability of the learning object interface include introducing relevant content according to the previous interaction between the student and the mediatic objects contained in the learning objects' interface. Thus, the learning objects' interface has to monitor the students' progress and to keep them aware of their own progress.

For the interface of a learning object to be adaptive and adaptable, we must consider the user model, instructional design and customization of the learning object.

\subsection{User Model}

A user model is a representation of the beliefs concerning the interests and preferences of a particular user [25]. The user model is continuously updated during the interactions of the user with the learning object interface. It allows implementing the adaptivity and adaptability of the learning object. The user model has two key elements: 1) Beliefs about the user interests and 2) Beliefs about the user preferences.

The user interests are inferred based on the selective actions of the user with educational mediatic objects. In the learning object, the user's interests serve as a basis for recommending relevant educational mediatic objects. The user preferences are determined based on the manual location of educational mediatic objects on the interface, by the user. The preferences cannot be deduced by the learning object, the user has to inform the learning object directly or indirectly (by a simple feedback) about such preferences [3].

As shown in Figure 1-a the adaptivity of the learning object depends on the user interests, represented in the user model, and the appropriate order of educational mediatic objects, represented in the instructional design (see Figure 1-a). On the other hand, the adaptability of the learning object depends on the user preferences about the location of educational mediatic objects; represented in the user model and the customization (see Figure 1-b). Therefore, we can say that an adaptive and adaptable learning object is the one that presents educational mediatic objects in the interface in an individualized and personalized way, facilitating user interaction.

To implement the user model is necessary to characterize a dynamic data structure that represents the system beliefs about individual user preferences and interests. Beliefs are generated based on the selective actions and location that the user has made over the mediatic objects. These records, handled as beliefs, should change dynamically according to user actions.

Basic beliefs are those that are created based on user interaction with educational mediatic objects, in carrying out a selective action on a mediatic object. Are considered basic beliefs to those beliefs based on evidence generated from user interaction with mediatic objects, with explicit or implicit belief. The selective actions are evidence to generate explicit and implicit beliefs about the user's interests. The user can explicitly indicate their interest in a mediatic object. On the other hand, if evidence exist that the frequent user interaction with a mediatic object given, will be expressing, implicitly, his interest in it. The location actions are evidence to generate explicit beliefs about the preferences of the user.

Derived beliefs are those beliefs generated based on the basic beliefs and metadata repository of mediatic objects. These derived beliefs are inferred from a basic belief about the interest of the user on a mediatic object and the frequency of use. This should be considered the mediatic objects that are linked through metadata for that learning object select which mediatic objects present at the interface. The relationship between mediatic objects, especially that allow their classification, allows derived beliefs are developed that represent a generalization of the user's interests with respect to content of mediatic objects. 


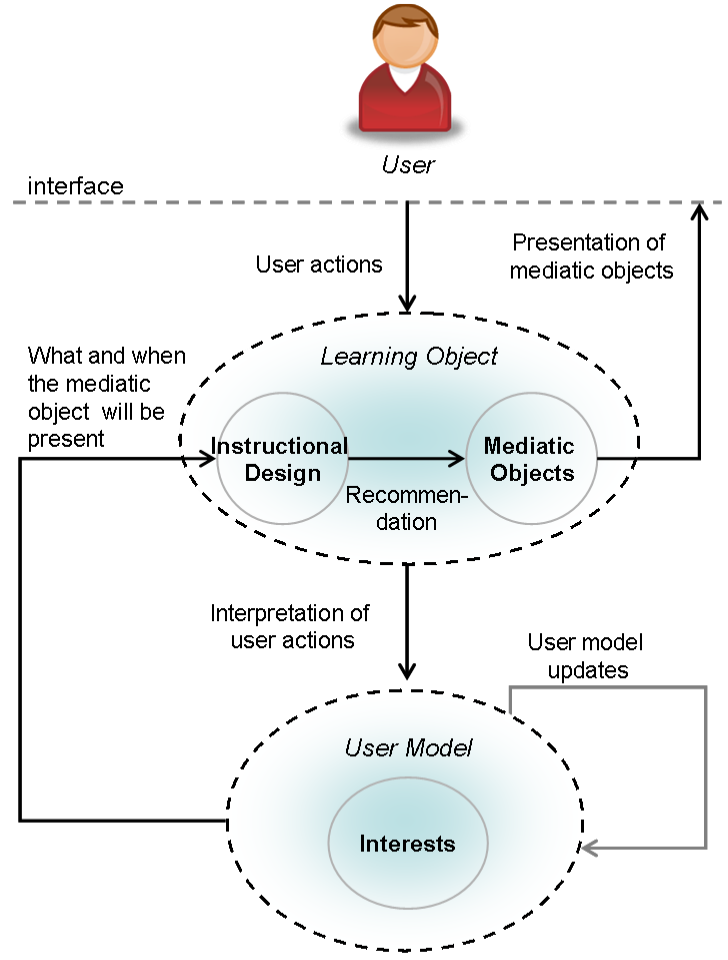

(a) Adaptivity

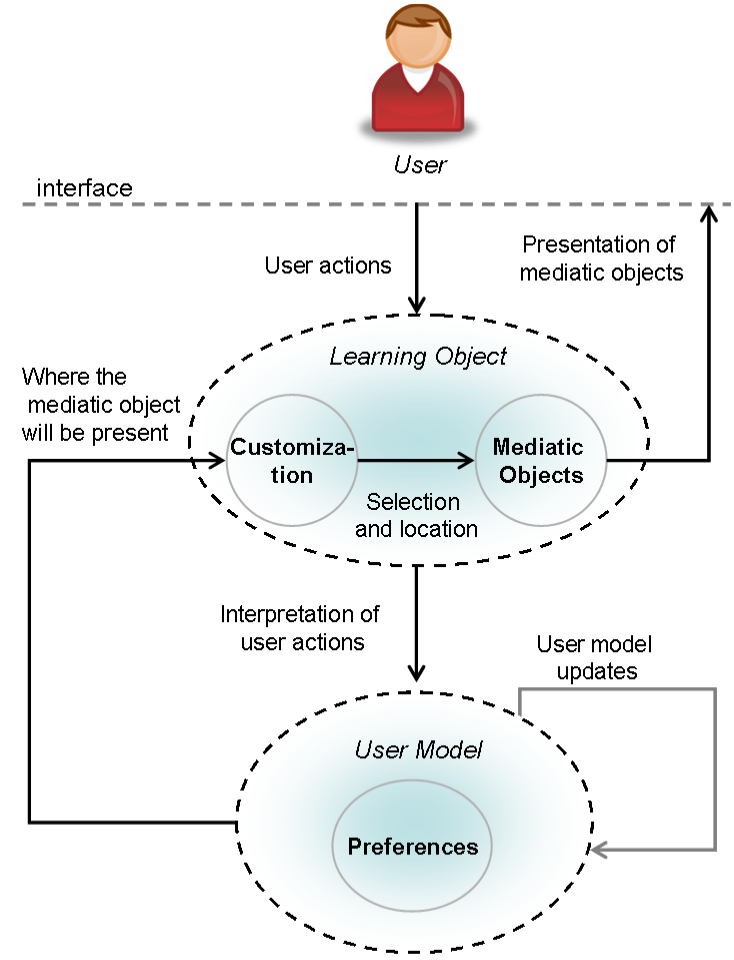

(b) Adaptability

Fig 1: Adaptivity and adaptability of the learning objects interface.

\subsubsection{User model representation}

\subsubsection{Belief degree}

The belief degree represents the probability that is assigned to a belief that a user has some interest in a specific section of the learning object. According to Paredes [22] it is calculated as follows:

$$
B d_{s}=\frac{N_{s}}{I}
$$

Where:

$\mathrm{Bd}_{\mathrm{s}}$ Belief degree about the interest of the user in a specific section.

Ns Total number of times that the user has selected the section.

I Total number of interactions with sections of the learning object from the user selected it for the first time.

\subsubsection{Adaptivity degree}

The adaptivity degree represents the consistency of the beliefs, according to the user opinion. According to Paredes [22], adaptivity degree is calculated as follows:

$$
A d=\frac{N c}{N s}
$$

Where:

Ad Adaptivity degree of the model.

$\mathrm{Nc}$ Number of beliefs confirmed by the user.

Ns Number of beliefs suggested by the model.

The adaptivity degree will increase each time the user performs a selective action on a section of the learning object the model has recommended according to their interests. When the user does not select any section recommended, the value of the interest degree on the section decreases.

\subsubsection{Interest threshold}

The interest threshold is a numerical value between 0 and 1 . It indicates from what value a learning object section should be considered of interest to a particular user. When a section has an interest degree equal or greater than interest threshold, the user model retains the belief that the user is interested in that section.

\subsubsection{Adaptivity threshold}

According to Paredes [22], the adaptivity threshold "indicates the percentage of reliability from which it is considered that the model is sufficiently adapted to the user and their beliefs are reliable basis for making decisions about it". This threshold indicates when the sections that the learning object presents are of interest for the user.

\subsubsection{Beliefs discard threshold}

This threshold is used in order to decide a decrement in the interest degree over a section of the learning object, and therefore it is not expected to increase again. If the interest 
degree has decreased the interest should be discarded on that section.

\subsubsection{Derived interest factor}

The derived interest factor (Fids) is "a numerical value between zero and one, representing the importance to be given the type of relationship that links the basic beliefs and beliefs derived" [21], that is, the relationship between sections of the learning object. For this constant should consider that the user is interested in a section related to another that has shown its interest. Derived beliefs are inferred from basic beliefs about the interest of the user a section of the learning object, looking for other related sections and assigning a value that includes the interest degree in the basic belief, interest derived factor and adaptivity degree of the model. According to Paredes [22], the derived belief degree is calculated as follows:

$$
B d_{d}=\left(B d_{b}\right)\left(F i d_{s}\right)(A d)
$$

Where:

$\mathrm{Bd}_{\mathrm{d}} \quad$ Derived belief degree.

$\mathrm{Bd}_{\mathrm{b}} \quad$ Basic belief degree.

Fid $_{\mathrm{s}}$ Delivered interest factor the relationship between sections.

Ad Adaptivity degree of the user model.

\subsubsection{User model updater}

An algorithm is required to implement the user model updater, capable to review the beliefs represented in the user model. This is necessary to maintain the consistency and be careful when replacing pervious beliefs with new ones. Positioning actions will generate beliefs about the user's preferences regarding the location of educational mediatic objects in the interface. Basic beliefs are those created based on user's direct interaction with educational mediatic objects, like a selective action on a mediatic object. Those beliefs based on evidence retrieved from user interaction with educational mediatic objects are considered basic beliefs and can be explicit or implicit. Positioning actions are evidence to create explicit beliefs about the preferences of the user.

In the elimination of basic beliefs about the user's interests is carried out in two situations. One refers to a decrease in the frequency of interaction with the educational mediatic object. Based on this, we can infer that the interest has declined, so that, the updater will remove the corresponding belief to reach the interaction frequency at a low level established or threshold. The other, refers to the explicit indication of the user that has no interest in the educational mediatic object. The elimination of derived beliefs about the user's interests is carried out when the updater eliminates the basic belief that used for its creation. On the other hand, for the elimination of basic beliefs about explicit user preferences, the updater must register the change of location that the user has previously performed on the mediatic object, so the updater will eliminate the belief about the mediatic object.

\subsubsection{User model monitor}

To implement the monitor, the interface must keep "listening" events related to user actions, to determine the creation or elimination of preference beliefs.

\subsection{Instructional Design}

Instructional design is the "process by which education is enhanced through the analysis of learning needs and systematic development of learning materials" [9]. In the context of this research, we consider the instructional design from two perspectives:

\subsubsection{Instructional design applied to the design of mediatic objects}

Instructional design applied to the design of mediatic objects. Is related to the design and development of each one of the learning object's contents, considering a set of instructional design elements as guidance (Table1). The learning object interface design requires not only to take into account the aesthetic and functional mediatic objects. It also considers metaphors, knowledge representation and meaning of content through the appropriate visualization [24].

Table 1. Instructional design elements considered in the design of mediatic objects

\begin{tabular}{|c|l|}
\hline Elements & \multicolumn{1}{|c|}{ Description } \\
\hline $\begin{array}{c}\text { Real } \\
\text { situation }\end{array}$ & $\begin{array}{l}\text { Allow the designer to enter into the user's } \\
\text { context. In this way, the designer can } \\
\text { determine the appropriate metaphor for the } \\
\text { representation of a mediatic object in } \\
\text { particular. }\end{array}$ \\
\hline Content & $\begin{array}{l}\text { The way the knowledge is represented in the } \\
\text { mediatic object and the form of representation } \\
\text { determined by the designer. }\end{array}$ \\
\hline $\begin{array}{c}\text { Strategies of } \\
\text { the facilitator }\end{array}$ & $\begin{array}{l}\text { The designer determines the appropriate } \\
\text { visual representation of the mediatic object for } \\
\text { the user, in order to achieve a signification of } \\
\text { the educational content. This refers to how the } \\
\text { designer achieves the understanding of the } \\
\text { user about what must be represented in a } \\
\text { mediatic object [11]. }\end{array}$ \\
\hline
\end{tabular}

\subsubsection{Instructional design applied to the design} of learning object

The application of the instructional design to the design of learning objects is relevant to design the interaction between user and mediatic objects (Table 2). Instructional design aids the environment to choose what, where and when the mediatic object will be displayed in the learning objects interface [26].

Table 2. Instructional design elements considered in the design of the learning objects

\begin{tabular}{|c|l|}
\hline Elements & \multicolumn{1}{c|}{ Description } \\
\hline Learning goal & $\begin{array}{l}\text { Is the learning objective to be achieved by } \\
\text { the user, interacting with the mediatic } \\
\text { objects of the learning object. }\end{array}$ \\
\hline $\begin{array}{c}\text { Characteristics } \\
\text { of } \\
\text { the user }\end{array}$ & $\begin{array}{l}\text { The mediatic objects should be designed } \\
\text { according to the general user profile (age, } \\
\text { gender, level, culture and community). }\end{array}$ \\
\hline $\begin{array}{c}\text { Navigation map } \\
\text { of }\end{array}$ & $\begin{array}{l}\text { Supports the free exploration and control of } \\
\text { the user during interaction. It is extremely } \\
\text { important to consider which mediatic } \\
\text { objects will be integrated into the interface } \\
\text { of the object and when they will be } \\
\text { recommended, in order to provide the user } \\
\text { cognitive scaffolding. }\end{array}$ \\
\hline $\begin{array}{c}\text { Task } \\
\text { management }\end{array}$ & $\begin{array}{l}\text { It is necessary to identify first the tasks that } \\
\text { the user can perform with the mediatic } \\
\text { objects, in order to determine which } \\
\text { activities will be presented to her/him and } \\
\text { their corresponding order. }\end{array}$ \\
\hline
\end{tabular}


For the implementation of instructional design is necessary to determine the symbols that allow us to visualize, specify and build the navigation relationships of the mediatic objects for the user to interact. Subsequently, we define a data structure that represents the navigation map of all educational mediatic objects of the learning object.

\subsection{Customization}

Customization refers to the user preferences about the location of mediatic objects in a particular place of the learning objects' interface. In the customization must be determined which educational mediatic objects can change their location in the interface, according to the user preferences and includes the definition of possible scenarios for displaying and positioning educational mediatic objects in the interface. Since these preferences could not be detected automatically by the learning object, this information will be provided directly by the user.

User interactions with educational objects should be monitored and registered, for the learning object to keep track of the location of educational mediatic objects in the interface. This location depends on the users "drag-and-drop" actions. Educational mediatic objects can be placed and maintain their location within the interface of the learning object. In order to do this, the ' $x$ ' and ' $y$ ' position of mediatic objects in the interface must be determined, establishing an active location zone for educational mediatic objects.

\section{ARCHITECTURE AND SOFTWARE ELEMENTS}

The design of a learning object interface implies the corresponding design processes for adaptivity and adaptability. Here we present the general architecture of our proposal and the detailed design as sequences of events. We propose ADA+ALOI (Architecture for the Design of Adaptivity and Adaptability of Learning Objects Interface). This architecture allows the presentation of educational mediatic objects at the interface of the learning object according to the interests and preferences of the user. The architecture is presented in Figure 2, and contains the following software components:

1. Monitor. Records and interprets each user action on the educational mediatic objects, detecting the user interests and preferences.

2. Updater. Updates the user model, updating or creating new beliefs about the user's interests and preferences.

3. Adaptivity module. It recommends what educational mediatic object and when to present them at the interface. This is done by presenting a navigation map of those mediatic objects believed to be of the user interest.

4. Adaptability module. Organizes, presents and maintains the location of educational mediatic objects at the interface, according to the user preferences.

5. Instructional design. Contains a representation of the navigation map of all mediatic objects in the learning object.

6. Mediatic objects. Repository of the mediatic objects of the learning object. It provides the metadata for each educational mediatic object under request.
7. User model. Representation of the set of beliefs concerning the interests and preferences of a particular user.

8. Interests. Beliefs about the user interests.

9. Preferences. Beliefs about the user preferred location of the educational mediatic objects.

\subsection{Sequence of events: Interface adaptivity}

The sequence of events for adaptivity of the learning objects interface is the following:

1. The learning object presents the educational mediatic objects in the interface, according to predetermined instructional design of the learning object.

2. The user interacts with educational mediatic objects at the interface of the learning object.

3. The monitor records and interprets those user selective actions on the educational mediatic objects. (These selective actions may include choosing an educational mediatic object, marking it as favorite, etc.).

4. The user model determines the user interests based on the interpretation of the selective actions of the user.

5. The adaptivity module makes a request of user interests to the user model.

6. The user model provides information regarding the user interests to the adaptivity module.

7. The adaptivity module proposes educational mediatic objects based on the user interests.

8. The instructional design module decides what, where, when the educational mediatic object will be displayed in the learning object interface according to the proposed educational mediatic objects.

9. The user interacts with those educational mediatic objects proposed by the instructional design module.

10. The monitor records the user selective actions on the proposed educational mediatic objects.

11. The updater module updates the user model according to the selective actions on the educational mediatic objects.

\subsection{Sequence of events: Interface adaptability}

The sequence of events for adaptability of the learning objects interface is the following:

1. The learning object presents the educational mediatic objects in the interface, according to their predetermined location in the learning object.

2. The user selects and locates some educational mediatic objects in the place s/he decides in the interface.

3. The monitor records the drag-and-drop user actions with the educational mediatic objects on the learning objects interface. 
4. The user model determines the user preferences, based on the registered locations.

5. The adaptability module makes a request of user preferences to the user model.

6. The user model provides information regarding the user preferences to the adaptability module.

7. The adaptability module organizes the educational mediatic objects on the learning objects interface, according to the user preferences.

8. The educational mediatic objects are presented in the container in the location preferred by the user.

9. The user interacts with the educational mediatic objects presented.
10. The monitor records the user actions with educational mediatic objects of the learning objects interface.

11. The updater maintains the user model according to the user actions.

\section{PROTOTYPE}

A high fidelity prototype was designed an adaptive and adaptable interface to explore the feasibility of the architecture described above. The prototype consisted in a learning object that was implemented considering our proposal. In this way, we identified which elements are represented in the interface, which mediatic objects will be displayed and what will be their purpose.

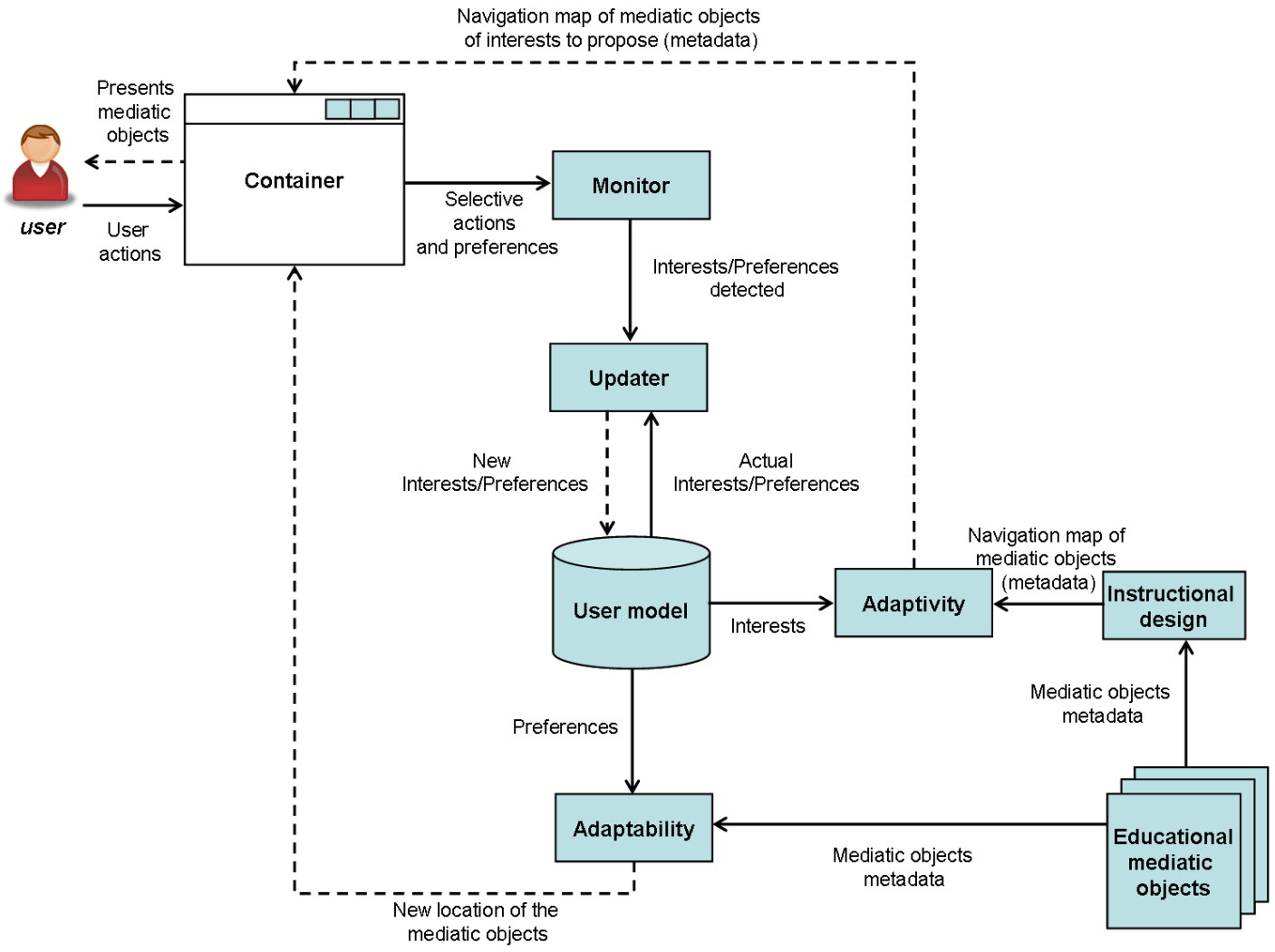

Fig 2: Architecture proposal for adaptivity and adaptability learning object's interface.

The distribution of mediatic objects in the interface was also determined based on their importance. In order to implement the adaptability, we identified active areas, where users can position educational mediatic objects to their preferences. The research also included the identification of educational mediatic objects that can change their position inside the interface, according to the user preferences. The learning objects have visual hints that indicate the possibility of positioning actions on the educational mediatic objects. The user can determine which educational mediatic object to move physically in the interface, according to his/her preferences (adaptability).

When the user completes the interaction with the learning object, the physical positions of educational mediatic objects are registered in the database. Thus, each time the user interacts with the learning object, the educational mediatic objects are maintained in the position chosen by the user. The database allowed to register in the case of educational mediatic objects, the " $x$ " and "y" position of the mediatic object.

In this way the user can perform positioning actions on the educational mediatic objects, which will be monitored and recorded in the database to keep the educational mediatic objects in the user's preferred location after his/her interaction with the learning object. The implemented database allowed us to store and manipulates the physical positions of the educational mediatic objects contained in the interface of the learning object. These physical positions change dynamically according to the positioning actions taken by the user each time s/he interacts with the learning object. Once the database was implemented, a server was developed upon it to receive the " $x$ " and " $y$ " position and change the location of educational mediatic objects according to positioning actions carried out by the user. It was possible to connect the learning object with the server for 
retrieving the positions recorded in the database and display educational mediatic objects in the learning object interface according to user preferences.

When the user completes the interaction with the educational mediatic objects of the sections of the learning object, its interests are recorded in the database. The user model generates beliefs about sections of the learning object and learning objects that may be of interest to the user based on their interests. Sections and learning objects considered of interest to the user are presented in the interface home page of the learning object. The user can choose which sections and learning objects are of interest (adaptivity)

\section{CONCLUSION}

The user must not adapt her/himself to the learning object. The learning object must adapt itself to the user. This adaptation implies the design of the learning object interface and the mediatic objects, which should imply the processes and structures for adaptivity and adaptability. The interface of a learning object should be defined as an action space where mediatic objects are displayed for the user to interact with them. The development of mediatic objects as the mediator elements between the interface of the learning object and the user makes possible the assignment of proper meaning to educational content. For this significance to be successfully achieved, concepts such as mediatic objects design, adaptivity design and adaptability design need to be considered within the design process of interface.

Adaptivity is the presentation of those educational mediatic objects considered of the interest of the particular user. Adaptability refers to the presentation of educational mediatic objects on the user's preferred location. The ADA+ALOI architecture (Architecture for the Design of Adaptivity + Adaptability of the Learning Object Interface) is a proposal for the design of an adaptive and adaptable learning objects interfaces, is based on a representation of the user interests and preferences. Our architecture implies a user model, where interests and preferences are registered, and an instructional design module, which represents the pedagogically oriented order of the contents. Learning objects with adaptive and adaptable interfaces allow to present educational mediatic objects in a personalized way, according to the user interests and preferences.

\section{REFERENCES}

[1] Battou, A. et. al, 2010: "The granularity approach of learning objects to support adaptability in adaptive learning systems". Journal of Theoretical and Applied Information Technology, Vol. 18. No. 1, 2010 Available online

at: http://www.jatit.org/volumes/eighteenth_volume_1_2010.p hp

[2] Botsios, S. and Georgiou D., 2009: "Using standards for adaptive learning objects retrieval". Journal of Knowledge and Learning, 2009. Available online at: http://utopia.duth.gr/ dgeorg/PUBLICATIONS/58.pdf

[3] Brusilovsky, P., 1996: "Methods and techniques of adaptive hypermedia". In P. Brusilovsky and J. Vassileva (eds.), User Modeling and User-Adapted Interaction 6 (23), Special Issue on Adaptive Hypertext and Hypermedia, 87-129.

[4] Chawla, S. and Singla R. K., 2010: "Mechanism for learning object retrieval supporting adaptivity”. Journal of Telecommunications, Volume 2, Issue 2, May 2010.
Available

online

at:

http://arxiv.org/ftp/arxiv/papers/1006/1006.0861.pdf

[5] Friesen, N., 2004: "Three objections to learning objects. Online education using learning objects". McGreal, R. Ed. London: Routledge, pp. 59-70. Available online at: http://www.learningspaces.org/n/papers/objections.html

[6] Galeana, L. y Cruz, G., 2005: "Los fundamentos biológicos del aprendizaje para el diseño y aplicación de objetos de aprendizaje", Revista CEUPROMED. Available online at: http://ceupromed.ucol.mx/revista/PdfArt/1/30.pdf

[7] Gkatzidou, S. and Pearson, E., 2008: "A vision for truly adaptable and accessible learning objects". Proceedings ascilite Melbourne, 2008. Available online at: http://www.ascilite.org.au/conferences/melbourne08/procs/ gkatzidou-poster.pdf

[8] Gkatzidou, S. and Pearson, E., 2010: "Exploring the development of adaptable learning objects. A practical approach". 10th IEEE International conference on advanced learning technologies ICALT 2010, in Proceedings. California: IEEE, pp. 307-309. Available online at: http://tees.openrepository.com/tees/bitstream/10149/11605 1/2/116051.pdf

[9] Instructional Design, 2009. Available online at: $\mathrm{http} / / / \mathrm{www}$.instructionaldesign.org/

[10] Ip, A., Morrison, I. and Currie, M., 2001: "What is a learning object, technically?". Web Net 2001 World Conference on the WWW and Internet, pp. 580-586. Available online at: http://users.com.au/adslfrcf/lo/learningObject(WebNet2001 ).pdf

[11] Jakobson, R., 1981. "Lingüistica y poética”, Madrid: Cátedra.

[12] Karampiperis, P. Sampson, D., 2006: "Adaptive Learning Objects Sequencing for Competence-Based Learning”. Proceedings of the 6th IEEE International Conference on Advanced Learning Technologies, July 5th-7th, 2006, [http://www.ask.iti.gr/icalt/2006], Kerkrade, The Netherlands, IEEE Computer Society Press. Available online at http://dspace.learningnetworks.org

[13] Kobsa, A., 2004: “Adaptive Interfaces", University of California, Irvine. Available online at: http://www.ics.uci.edu/ kobsa/papers/2004-HCIEncyclopedia-kobsa.pdf

[14] Koch, N., 2000: "Software Engineering for Adaptive Hypermedia Systems". PhD thesis, Ludwig-MaximiliansUniversity Munich, Germany. Available online at: http://www.pst.informatik.unimuenchen.de/personen/kochn /PhDThesisNoraKoch.pdf

[15] LSTC: "Learning Technology Standards Committee". Available on line at: htt://ltsc.ieee.org/

[16] Magenheim, J. and Scheel, O., 2004: "Integrating learning objects into an open learning environment: evaluating of learning processes in an informatics learning lab". Proceedings of the 13th international World Wide Web Conference on Alternate Track Papers \& Amp; New York, USA, May 19th - 21st WWW Alt. '04. ACM Press, pp. 450-451. 
[17] Merril, D., 2000: "Instructional transaction theory (ITT): Instructional design base on knowledge objects", Chapter 17 in C. M. Reigeluth (Ed.), Instructional-Design Theories and Models: A New Paradigm of Instructional Theory. Mahwah, NJ: Lawrence Earlbaum Associates. Available online http://cito.byuh.edu/merril/text/papers/7ReigChp.PDF

[18] Merril, D., 2002: "Knowledge Objects and Mental Models. The instructional use of learning objects". Wiley, D. A. ed. Instructional Use of Learning Objects: Online Version. Washington DC: Agency for Instructional Technology and Association for Educational Communications and Technology. Available online at: http://reusability.org/read/chapters/merril.doc

[19] Milosevic, D. and Brkovic, M., 2007: "Adaptive learning using SCOs metadata". Interdisciplinary Journal of Knowledge and Learning Objects, Volume 3, 2007. Available online at: http://ijello.org/Volume3/IJKLOv3p163-174Milo326.pdf

[20] Nguyen, L. and Phung, D., 2008: "Learner model in adaptive learning". World Academy of Science, Engineering and Technology, 2008. Available online at: http://www.waset.org/journals/waset/v45/v45-70.pdf

[21] Oppermann, R, 1997.: "Adaptability and Adaptivity in Learning Systems”, GMD FIT-German National Research Center for Information Technology. Available online at: http://www.fit.fraunhofer.de/ oppi/publications/kt97_gmd. pdf

[22] Paredes, R. and Ayala G., 2001: "Learner model servers: personalization of web based educational applications base don digital collections". World Conference on Educational Multimedia, Hypermedia and Telecommunications (EDMEDIA), Honolulu, Hawaii, USA. ISBN 1-880094-487.

[23] Polsani, P., 2003: "Use and Abuse of Reusable Learning Objects". Journal of Digital Information, Vol. 3 Issue 4, No. 164, February 19th 2003. Arizona, USA.
[24] Rodríguez, V., Ayala, G., 2008: "Diseño de la Interfaz del Objeto de Aprendizaje: Asegurando la Coherencia entre los Objetos Mediáticos”, Memorias de la Tercera Conferencia Latinoamericana de Tecnología de Objetos de Aprendizaje, LACLO 2008, Aguascalientes, Aguascalientes, México, pp. 269-277.

[25] Rodríguez, V., Ayala, G., 2009: "Adaptatividad y Adaptabilidad de la Interfaz del Objeto de Aprendizaje", Memorias de la Conferencia Conjunta Iberoamericana sobre Tecnologías para el Aprendizaje 2009, CCITA 09, Mérida, Yucatán, México, pp. 429-434.

[26] Rodríguez, V., Ayala, G., 2009: “Adaptivity and Adaptability in Learning Objects", Learning Technology NewsLetter (October 2009) publication of IEEE Computer Society Technical Technology (TCLT) special issue on Learning Objects and Their Supporting Technologies for Next Generation Learning, pp. 32-35. Available online at: http:// www.ieeetclt.org/issues/october2009/lt_oct2009.pdf

[27] Shepherd, C., 2000: “Objects of interest". Available online at: http://www.fastrakconsulting.co.uk/tactix/features/objects/objects.htm

[28] Sicilia, M., García, E., Sánchez, S. and Rodríguez, E., 2004. "Describing Learning Object Types in Ontological Structures: Towards Specialized Pedagogical Selection". In L. Cantoni \& C. McLoughlin (Eds.), Proceedings of World Conference on Educational Multimedia, Hypermedia and Telecommunications, pp. 2093-2097. Chesapeake, 2004. VA: AACE.

[29] Wiley, D., 2002: “Connecting learning objects to instructional design theory: A definition, a metaphor, and a taxonomy". Wiley, D. A. ed. Instructional Use of Learning Objects: Online Version. Washington DC: Agency for Instructional Technology and Association for Educational Communications and Technology, 2002. Available online at: http:// reusability.org/read/chapters/wiley.do 